ciate that the question posed could only be determined by means of an enlarged study.

M J GARDNER

University Department of

Community Medicine,

Southampton

A H JAMES

Department of Medicine,

Hillingdon Hospital,
Uxbridge, Middx

Armitage, P, Statistical Methods in Medical Research. Oxford, Blackwell, 1971.

\section{Ten-minute abortions}

SIR,-Mr W O Goldthorp (27 August, p 562) is correct when he says that the law on abortion in Britain refers to acts intended to interrupt pregnancy, whether or not a pregnancy exists. I submit, therefore, that he should notify the Chief Medical Officer after all his aspirations, perhaps using the complications section of the form to indicate if a woman was not pregnant.

If it becomes a common practice to withhold notification of abortions when there is no histological proof of the products of conception it will not be long before the diagnosis of pregnancy is ignored both after as well as before ethical and statistical confusion.

David MillaR

Sheffield

\section{Hyperglycaemia and complications of diabetes}

SIR,-On the basis of their very impressive finding of a relationship, in rats with pancreatic islets damaged by streptozotocin, between mean plasma glucose value and renal basement membrane thickness $\mathrm{Dr} C \mathrm{~J}$ Fox and his colleagues (3 September, p 605) hope that doctors treating diabetics will be encouraged to pursue good control of glucose levels. This wish is strengthened by results from the Oxford diabetic clinic on patients observed for the first three years after diagnosis. Vibration sense was assessed with a biothesiometer and recorded as the sum of the mean of three readings at each of four sites, the two halluces and the two external malleoli. The results, now submitted for publication elsewhere, are summarised in the accompanying table. Although vibration sense did not change significantly over the three years when calculated for the whole group, it deteriorated in those with the higher plasma glucose values and improved in those with the lower values.

We had the advantage of dealing with natural human diabetes, here of "maturitytype onset," which certainly involves isletcell deficiency but may not be exactly comparable in effect to streptozotocin-induced
Southampton General Hospital, the procedure. This would produce both

damage, but at a disadvantage in that the two groups were not comparable initially in plasma glucose concentration, for those with higher mean fasting glucose levels tended to have higher values before treatment started. It is not surprising that those in this group were also much more likely to be treated wih sulphonylureas, but this is comparable to administration of insulin to some rats in the experiments reported by $\mathrm{Dr}$ Fox and his colleagues.

We have examined a type of diabetic tissue damage different from the rat's renal microangiography, but large-nerve damage also causes much morbidity. It is most encouraging that Dr Fox and his colleagues have obtained a similar result from the speed of conduction in motor nerve fibres.

\section{T D R HOCKADAY} J I MANN Radcliffe Infirmary,
Oxford

\section{Deafness due to Paget's disease of bone}

SIR,-The involvement of the labyrinthine capsule of the inner ear by Paget's disease seems to be largely responsible for the severe sensorineural deafness that may occur. Treatment with calcitonin aims to retard and if possible arrest this process in the active phase in the same way that fluoride therapy is used for labyrinthine otosclerosis. The value of these protracted forms of treatment is uncertain, but the most recent report, by $\mathrm{Dr} L \mathrm{R}$ Solomon and others (20 August, p 485), is favourable. They based the selection of patients for treatment on typical audiological changes and radiological evidence of Paget's disease of the skull but did not do temporal bone tomography "because of the risks to the eye."

This is an incredible statement, which presumably refers to the radiation dose to the eyes during temporal bone tomography. A previous publication from Manchester ${ }^{1}$ showed a mean corneal radiation dose of 10 rads during temporal bone tomography, which was greatly reduced by using lead eyeshields. However, patients undergoing extensive neuroradiological procedures, including computerised tomography, may receive a cumulative corneal dose in excess of 60 rads. If lead eyeshields are used or tomography is done with the patient in the prone position the total radiation dose to the eyes may be less than that delivered for one Towne's view."

In otosclerosis demineralised foci with blurring and thickening of the labyrinthine capsule are well shown by multidirectional tomography. The tomographic appearances are therefore used to select patients for fluorid therapy and then to assess the progress of the disease and the effect of treatment. ${ }^{3}$ In Paget's disease similar demineralisation and thickening of the labyrinthine capsule may be demonstrated as well as the more common narrowing

Biothesiometer readings (mean $\pm S E M$ ) as sum of mean of readings at four separate sites on feet (high value indicates insensitivity)

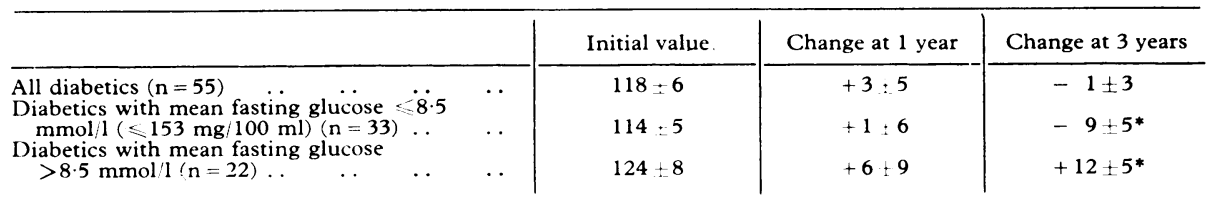

*Difference between means, $\mathrm{P}<0.005$ and distortion of the internal auditory meatus which may also be responsible for sensorineural deafness. In my opinion therefore tomography, while being no danger to the eyes, is necessary to show the presence and extent of Paget's disease of the temporal bone. This information, with the audiometric results and repeat tomograms to assess progress, would enhance the value of any survey of the use of calcitonin in deafness due to Paget's disease.

Peter D Phelps

Walsgrave Hospital

Coventry

'Isherwood, I, et al, Neuroradiology, 1975, 10, 137 Ashley, A J, Radiography. In press.

Shambaugh, G E, and Causse, J, Annals of Otology, Rhinology and Laryngology, 1974, 83, 635 .

\section{Antilipolytic effects of beta-blocking drugs}

SIR,-I was interested to read the paper by Dr R J Newman (3 September, p 601) reporting the acute antilipolytic effects of acebutolol, metoprolol, and propranolol. Predicting the expected antilipolytic effect of $\beta$-adrenoceptor blocking drugs is difficult, for the precise physiological mechanisms controlling lipolysis have not yet been defined. In a similar study I have suggested that basal lipolysis is mediated by $\beta_{1}$-adrenoceptors and that stressinduced lipolysis is mediated by both $\beta_{1}$ - and $\beta_{2}$-adrenoceptors. This is supported by studies showing that atenolol is as effective as propranolol in lowering basal plasma nonesterified fatty acid (NEFA) concentrations ${ }^{1}$ and that, while atenolol ${ }^{1}$ and practolol $^{2}$ reduce stress-induced lipolysis, they are not as effective as oxprenolol ${ }^{3}$ or propranolol. ${ }^{4}$ However, it is uncertain whether lipolysis is mediated by an increase in circulating catecholamines or by increased sympathetic nervous activity, or both. Other pharmacological properties of $\beta$-blocking drugs may influence their metabolic effects, and Dr Newman's general comments are open to criticism for he neglects to discuss the possible effects of relative $\beta$-adrenoceptor specificity, intrinsic sympathomimetic activity, and water-lipid solubility and also the possibility that more than one adrenergic mechanism may mediate lipolysis. For instance, pindolol, a nonselective $\beta$-blocker possessing intrinsic sympathomimetic activity, has been shown to produce a small but significant rise in basal plasma $\mathrm{NEFA}^{5}$ and not to affect the plasma NEFA response to insulin stress. ${ }^{6}$

While most $\beta$-blocking drugs do seem to have some acute antilipolytic effect, the effect of chronic administration might be different. Tanaka et $a l^{7}$ have shown that although propranolol initially lowered plasma NEFA levels, several weeks later increased levels were observed. Similarly, Waal-Manning ${ }^{8}$ had reported that raised triglyceride levels occurred following three months' administration of metoprolol, although Nilsson $e t a l^{9}$ in a controlled study with metoprolol showed no significant effect. Likewise, Ghosh et al ${ }^{10}$ have shown long-term practolol therapy to have no significant lipolytic effects. It seems therefore that the net in-vivo lipolytic effects of $\beta$ blocking drugs may be dependent upon several pharmacological properties and there may be individual variation. Studies in normal subjects may not be applicable to patients, especially those with disorders of lipid metabolism, and as I suggested in a recent 
letter (16 April, p 1033) long-term studies are needed to investigate the effects of $\beta$-blockade in such patients.

\section{S P DEACON}

Pilgrim Hospital,
Boston, Lincs

'Deacon, S P, British fournal of Clinical Pharmacology.

In press.
Sirtori, C R, et al, Pharmacological Research Com munications, $1972,4,123$.
Sirtori, $\mathrm{C}$.

Carruthers, M E, and Taggart, P, British Medical fournal, 1973, 3, 384.

Pinter, E J, and Pattee, C, Fournal of Clinical Endo crinology, 1967, 27, 1441 .

Schlierf, G, et al, European fournal of Clinical Pharmacology, 1973, 5, 154.

schrift, 1972, 102, 510

Tanaka, N, et al, Metabolism, 1976, 25, 1071.

Waal-Manning, H J, Drugs, 1976, 25, 1071.

Nilsson, A, et al, European fournal of Clinical Pharmacology. In press.

10 Ghosh, P, et al, Lancet, 1975, 1, 9.

\section{Bruising in thyrotoxicosis}

SIR,-I wish to report briefly the case of a woman with long-standing thyrotoxicosis whose presenting complaint was of bruising in order to inquire whether similar patients have been encountered.

The patient, aged 47 , was suspected of having thyrotoxicosis some four years before hospital consultation, which was delayed because, although her goitre and eye signs were typical, she had los very little weight. However, in this time she had started to bruise spontaneously and often excessively on the limbs. Her serum thyrosine concentration was elevated at $245 \mathrm{nmol}(19 \mu \mathrm{g} 100 \mathrm{ml})$ and her 4 -h radioiodine tracer uptake was $48^{\circ}$. The platelet count was $180 \cdot 10^{9} / 1\left(180000 / \mathrm{mm}^{3}\right)$ and her prothrombin time and other coagulation tests normal. The factor VIII level was $1.5 \mathrm{~g} / 1$ and that of factor IX $1.1 \mathrm{~g} / 1$. The antinuclear factor and latex tests were negative.

Mild spontaneous bruising in some women is not uncommon. In this case I wonder whether continued catabolism has resulted in a thinning of her basement membranes. The Hess test produced a very florid petechia reaction. Indeed, in the converse situation of myxoedema it is recognised that the lamina densa of the vascular basement membranes is thick and dense. ${ }^{1}$

E N WARDLE

Memorial Hospital,
Darlington, Co Durham

'McFadden, P M, and Berensen, G S, Circulation,
1972, 45, 808.

\section{Cephalic motor responses in brain death}

SIR,-Working as clinical neurologists we are consulted routinely in cases of probable brain death. We have welcomed the newly issued codes of practice, such as the Harvard criteria, ${ }^{1}$ those of the Conference of Medical Royal Colleges and their Faculties, ${ }^{2}$ and those of the collaborative study sponsored by the US National Institutes of Neurological Diseases and Stroke $^{3}$ as guidance in this very delicate matter. Recently, however, certain clinical findings have disturbed us.

While some patients have indisputably fulfilled the criteria of brain death, including the uniquivocal diagnosis of the cause of structural brain damage, lack of spontaneous respiration, absence of certain brainstem reflexes (fixed, unresponding pupils, absence of corneal, vestibular, and gag reflexes), and, in some cases, flat EEG, still some motor responses have been present, even shortly after the cardiac standstill which has eventually resulted from the disconnection of the patient from the artificial respirator. Tapping of the area above the eyebrows has repeatedly elicited noticeable contraction of the frontal muscle, indicated by upward movement of the eyebrow. Also tapping of the body of the masseter muscle has repeatedly caused a sharp upward movement of the chin as a reflection of contraction of the muscle. Chvostek's sign has been present in all these cases.

According to established neurophysiological knowledge at least, the contractions of the frontal and masseter muscles represent normal muscle stretch reflexes, which reflect patency of the reflex arc and thus also normal function of the motor nuclei of the trigeminal and facial nerves in the brainstem. Chvostek's sign, on the other hand, is considered to be a sign of local tetany reflecting low serum calcium content. But nevertheless it is a motor response.

It would be interesting to know whether other clinicians have had similar experiences and how the appearance of the phenomena described above should be interpreted. Should the patients be cared for as long as these signs are present, even though all the other brainstem reflexes had long been gone? Or should some revisions still be made in the criteria for the diagnosis of brain death?

Matti Jokelainen Reijo Marttila

Department of Neurology,

Lahti Central Hospital, ' Conference of Medical Colleges and their Faculties in
the United Kingdom, British Medical fournal, 1976, 2, 1187.

foc Committee of Harvard Medical School, 205, 337 . Collaborative Study, Journal of the American Medical
Association, 1977, 237, 982 .

Gonadotrophin deficiency and adrenocortical insufficiency in children

SIR, - I can confirm the suggestion of Dr W F Kelly and his colleagues (9 July, p 98) that this syndrome "will . . . be recognised more frequently now that cortisone-treated children will be surviving long enough to manifest the hypogonadal component."

In 1974 we examined a 21-year-old boy because of eunuchoid gigantism. At the age of 4 years he had been referred to the paediatric department for abdominal pain, vomiting, profound fatigue, and hypoglycaemia which had developed in the course of acute bronchitis. Hypocortisolism was confirmed biochemically and treatment with hydrocortisone was instituted. At the age of 20 his height was $201.8 \mathrm{~cm}$ and weight $105.5 \mathrm{~kg}$. There were no signs of puberty and the testes did not show pubertal growth. The following results of endocrinological examinations were obtained.

Plasma testosterone $4 \cdot 2 \mathrm{nmol} / 1(0 \cdot 12 \mu \mathrm{g} / 100 \mathrm{ml})$ (normal $17-28 \mathrm{nmol} / 1(0 \cdot 5-0.8 \mu \mathrm{g} / 100 \mathrm{ml})$ ). Basal serum luteinising hormone $3 \mathrm{IU} / 1$ (normal 5-20 IU/1); after luteinising hormone-releasing hormone (LH-RH) $(100 \mu \mathrm{g}$ intravenously) $7.5 \mathrm{IU} / 1$ (normal maximal increase 20-80 IU/1). Basal serum folliclestimulating hormone 2.1 IU/1 (normal 5-15 IU/1); after LH-RH $2.4 \mathrm{IU} / 1$ (normal maximal increase $1-6 \mathrm{IU} / 1)$. Serum thyroxine $116 \mathrm{nmol} / \mathrm{l}(9.0 \mu \mathrm{g} /$ $100 \mathrm{ml}$ ) (normal $70-160 \mathrm{nmol} / 1 \quad(5 \cdot 4-12 \cdot 4 \mu \mathrm{g} / 100$ $\mathrm{ml})$ ). Basal serum thyrotrophin (range) $4 \cdot 7-7 \cdot 0$ $\mathrm{mU} / 1$ (normal $<8.0 \mathrm{mU} / \mathrm{l}$ ); after thyrotrophinreleasing hormone (TRH) $(200 \mu \mathrm{g}$ intravenously) $20 \mathrm{mU} / 1$ (normal maximal increase $4-15 \mathrm{mU} / \mathrm{l}$ ).
$<15 \mu \mathrm{g} / \mathrm{l}$ ); after TRH $26 \mu \mathrm{g} / 1$ (normal maximal increase $15-40 \mu \mathrm{g} / \mathrm{l})$; after chlorpromazine $(25 \mathrm{mg}$ intramuscularly) $9 \mu \mathrm{g} / 1$ (normal maximal increase $15-60 \mu \mathrm{g} / \mathrm{l}$ ). Growth hormone $1 \mu \mathrm{g} / 1$ (normal $<5 \mu \mathrm{g} / \mathrm{l})$; after insulin $(0.1 \mathrm{U} / \mathrm{kg}$ body weight intravenously) $8 \mu \mathrm{g} / 1$ (normal peak value $>7 \mu \mathrm{g} / \mathrm{l}$ ) after levodopa ( $500 \mathrm{mg}$ by mouth) $10 \mu \mathrm{g} / 1$ (normal peak value $>7 \mu \mathrm{g} / \mathrm{l})$. Basal plasma cortisol at $7 \mathrm{am} 168 \mathrm{nmol} / 1 \quad(6.1 \mu \mathrm{g} / 100 \mathrm{ml}$ ) (normal 140$690 \mathrm{nmol} / \mathrm{l} \quad(5-25 \mu \mathrm{g} / 100 \mathrm{ml})$; after synthetic ${ }^{1-24}$ corticotrophin $(0.25 \mathrm{mg}$ intravenously) 146 $\mathrm{nmol} / \mathrm{l} \quad(5.3 \mu \mathrm{g} / 100 \mathrm{ml})$. Urinary 17-hydroxycorticosteroids unmeasurable (normal $17-48 \mu \mathrm{mol} /$ $24 \mathrm{~h}(5-14 \mathrm{mg} / 24 \mathrm{~h})$; after metyrapone $(4.5 \mathrm{~g}$ by mouth) $2.42 \mu \mathrm{mol} / 24 \mathrm{~h}(0.7 \mathrm{mg} / 24 \mathrm{~h})$; after synthetic ${ }^{1-24}$ corticotrophin $(0.25 \mathrm{mg}$ in 8 -hour infusion for three days) unmeasurable. Steroid examinations were performed while the patient was temporarily on fludrocortisone.

I believe that this is another case of the syndrome of gonadotrophin deficiency and adrenocortical insufficiency. Moreover, there was a lack of prolactin stimulation by chlorpromazine with preservation of stimulation by TRH. This finding may support the presumed hypothalamic aetiology of the gonadotrophin deficiency and indicate a disturbance of the hypothalamic dopaminergic system.

JOSEF MAREK

Third Department of Medicine,

Charles University,

Prague, Czechoslovakia

\section{Primary cutaneous actinomycosis}

SIR,-Despite the fact that 20-40 cases of actinomycosis are reported annually in the United Kingdom, ${ }^{1}$ primary cutaneous actinomycosis is extremely rare. The following is the fourth case to be added to the literature."

A 60-year-old Negro woman presented with a seven-week history of a growing abdominal mass. Eleven years previously an uncomplicated truncal vagotomy and pyloroplasty had been carried out for chronic duodenal ulceration. She looked well and was healthy generally and orodentally. The abdominal mass was $3.5 \mathrm{~cm}$ in diameter; it was situated in the abdominal wall at 10 o'clock to the umbilicus. It was tender and soft centrally but hard peripherally. Routine haematological and biochemical tests were normal, as was the chest $x$-ray. An initial diagnosis of a necrotic and malignant secondary was made.

At exploration yellow pus with obvious "sulphur granules" was obtained. A search for foreign bodies and for intraperitoneal and umbilical connections was negative. A biopsy specimen of the abscess wall was taken and the cavity drained. Whole pus was examined immediately and the diagnosis of actinomycosis confirmed. Pus culture later on grew Actinomyces israeli and anaerobic streptococci. Histological examination of the abscess wall also showed classical "sulphur granules." The pus swab taken at operation, on the other hand, proved of no significant bacteriological value as compared with the examination of the whole pus. This, in fact, may explain some of the failures to diagnose actinomycotic infections. Intramuscular penicillin, $2 \mathrm{MU}$ daily for one week followed by $1 \mathrm{MU}$ daily for six more weeks, was given. The abscess showed no sign of recurrence on review one year later.

It is accepted that the source of actinomycotic infection is almost invariably endogenous, although it has been reported after a human bite. ${ }^{3}$ Haematogenous spread from a primary focus is well documented. ${ }^{4} A$ israeli does not cross intact gastrointestinal mucosa and hence abdominal infections with this organism are usually associated with surgery, trauma, or viscus perforaticn. It is possible that the abscess in this case was secondary to the operation performed 11 years previously; 